\title{
Membrane Transport Influences the Rate of Accumulation of Cytosine Arabinoside in Human Leukemia Cells
}

\author{
J. Courtland White, ${ }^{\star \ddagger}$ James P. Rathmell, ${ }^{\star *}$ and Robert L. Capizzi ${ }^{\star 8}$ \\ ${ }^{*}$ Oncology Research Center and the Departments of ${ }^{\ddagger}$ Biochemistry and ${ }^{\$}$ Medicine, Bowman Gray \\ School of Medicine, Wake Forest University, Winston-Salem, North Carolina 27103
}

\begin{abstract}
The role of membrane transport in the cellular accumulation of 1- $\beta$-D-arabinofuranosylcytosine (ara-C) was studied in freshly isolated human acute leukemia cells. Patient cells had low rates for ara-C transport as compared with human and murine experimental cells and correspondingly low binding capacities for the nucleoside transport inhibitor, nitrobenzylmercaptopurine riboside (NBMPR). At $1 \mu \mathrm{M}$ ara-C, the rate of net cellular accumulation was close to the membrane transport rate, and NBMPR inhibited transport and accumulation to the same extent. The rate of ara-C accumulation was half maximal at only 3-5 $\mu \mathrm{M}$, a level much lower than that required for murine cells (67-85 $\mu \mathrm{M})$. At concentrations below $1 \mu M$ the rate of ara-C accumulation was determined primarily by the transport rate, but at higher concentrations above $10 \mu \mathrm{M}$, phosphorylation capacity was the principal determinant of the net uptake rate. This difference in the role of transport at high and low ara-C concentrations may explain, in part, the efficacy of high-dose ara-C in patients refractory to standard dose protocols.
\end{abstract}

\section{Introduction}

$1-\beta$-D-arabinofuranosyl cytosine (ara-C) ${ }^{1}$ is the most effective antimetabolite for the treatment of acute myelogenous leukemia (AML) (1). The clinical importance of ara-C has stimulated extensive laboratory investigations aimed at understanding biochemical correlates of drug action and mechanisms of drug resistance to provide ideas for better therapeutic strategy. Cytotoxicity has been correlated with the cellular accumulation of ara-C triphosphate (ara-CTP) (2) and its incorporation into DNA (3-5). Among the prerequisites for cellular accumulation of ara-

Address correspondence to Dr. White, Department of Biochemistry, Bowman Gray School of Medicine, 300 South Hawthorne Road, Winston-Salem, NC 27103.

Received for publication 26 November 1984 and in revised form 8 August 1986

1. Abbreviations used in this paper: AML, acute myelogenous leukemia; ALL, acute lymphoblastic leukemia; ara-C, 1- $\beta$-D-arabinofuranosyl cytosine; ara-CMP, ara-C monophosphate; ara-CTP, ara-C triphosphate; ara- $\mathrm{U}$, uracil arabinoside; $C_{\mathrm{t}}$, transport control strength; $\mathrm{CDP}$, cytosine diphosphate; $K_{\mathrm{p}}$, intracellular ara-C concentration for half-maximal phosphorylation; $K_{\mathrm{t}}$, transport $K_{\mathrm{m}} ; \mathrm{LB}-\mathrm{Pt}$, leukemic blasts isolated directly from patients; NBMPR, nitrobenzylmercaptopurine riboside; $V_{\mathrm{p}}, V_{\max }$ for phosphorylation.

J. Clin. Invest.

(c) The American Society for Clinical Investigation, Inc.

$0021-9738 / 87 / 02 / 0380 / 08 \quad \$ 1.00$

Volume 79, February 1987, 380-387
CTP are transport of ara-C across the cell membrane and phosphorylation of deoxycytidine kinase. Enhancement of the activity of deoxycytidine kinase through biochemical modulation has been a major research focus, and resistance to ara-C has been related to deficient phosphorylation capacity $(6-12)$. The role of membrane transport as a determinant of ara-C action in human leukemia has been relatively less explored.

Ara- $\mathrm{C}$ has been shown to be a substrate for the facilitated diffusion system for nucleosides $(13,14)$. In experimental tumor cells, the rate of ara-C transport is in significant excess of the rate of intracellular phosphorylation $(13,14)$. These observations have led to the conclusion that transport will not be an important determinant of ara-C action. However, the studies by Wiley et al. (15-17) with leukemic blasts isolated directly from patients (LB-Pt) have demonstrated that these cells have substantially lower ara-C transport capacity as compared with established tumor cell lines. In addition, myeloblasts had relatively higher transport capacities and formed more ara-CTP than lymphoblasts (15-17). Cells from a small group of AML patients who did not respond to ara-C had low ara-C transport capacity (15).

The present study was undertaken to examine the role of transport as a determinant of the rate of ara- $\mathrm{C}$ phosphorylation in LB-Pt at concentrations achieved in plasma during standard dose and high dose ara-C clinical protocols.

\section{Methods}

Materials. Minimum essential medium with Earle's salts and $2 \mathrm{mM}$ glutamine (Flow Laboratories Inc., McLean, VA) was supplemented with $20 \mathrm{mM}$ MOPS (pH 7.4) for use in transport, accumulation, and nitrobenzylmercaptopurine riboside (NBMPR)-binding experiments. FicollPaque $(d=1.077 \mathrm{~g} / \mathrm{ml})$ was purchased from Pharmacia Fine Chemicals (Piscataway, NJ). Di-n-butyl phthalate and di-n-octyl phthalate (Aldrich Chemical Co., Milwaukee, WI) were blended 4:1 (vol/vol) to yield an oil mixture of $d=1.03 \mathrm{~g} / \mathrm{ml}$. Dow Corning silicone oils 200 and 550 (William F. Nye, Inc., New Bedford, MA) were blended 16:84 to also yield $d=1.03 \mathrm{~g} / \mathrm{ml}$. Silicone oil was substituted for phthalate oil late in this study because $\left[{ }^{3} \mathrm{H}\right] \mathrm{NBMPR}$ was found to partition into phthalate oil. $\left[{ }^{3} \mathrm{H}\right]$ ara- $\mathrm{C},\left[{ }^{3} \mathrm{H}\right]_{2} \mathrm{O}$, and $\mathrm{L}\left[1-{ }^{14} \mathrm{C}\right]$ sucrose were obtained from Amersham Corp. (Arlington Heights, IL). $\left[{ }^{3} \mathrm{H}\right] \mathrm{NBMPR}$ and $\left[{ }^{3} \mathrm{H}\right]$ uracil arabinoside (ara-U) were obtained from Moravek Biochemicals, Inc. (Brea, CA). Samples of $\left[{ }^{3} \mathrm{H}\right]$ ara-C and $\left[{ }^{3} \mathrm{H}\right] \mathrm{NBMPR}$ were analyzed by reversephase high performance liquid chromatography (HPLC) and found to be $>92$ and $96 \%$ pure, respectively. Biochemicals and Sephadex A25 were obtained from Sigma Chemical Co. (St. Louis, MO). Aqueous samples were counted with aqueous counting scintillant (Amersham Corp.) in a single liquid phase. Samples were counted on a LS1801 liquid scintillation counter (Beckman Instruments Inc., Fullerton, CA) with automatic quench correction based on external standards.

Patient data. Adult acute leukemia patients had peripheral white counts ranging from 23,000 to $350,000 / \mu$ l with $90-95 \%$ blasts. Cytologic diagnosis was made in accord with French-American-British criteria (18). Informed consent was obtained from patients in accord with federal institutional guidelines. Studies were conducted at initial diagnosis and/ 
or at relapse; the latter patients had not had any chemotherapy for $>30$ $\mathrm{d}$ before these studies.

Preparation of human leukemic cell suspensions. Anticoagulated EDTA bone marrow aspirates and/or venous blood samples were layered over Ficoll-Paque and centrifuged at $400 \mathrm{~g}$ for $30 \mathrm{~min}\left(18^{\circ} \mathrm{C}\right)$. Cells at the plasma-Ficoll interface were harvested and washed twice with $5 \mathrm{ml}$ of phosphate-buffered saline (PBS) $\left(0.14 \mathrm{M} \mathrm{NaCl}\right.$ and $0.01 \mathrm{M} \mathrm{KH}_{2} \mathrm{PO}_{4} /$ $\mathrm{K}_{2} \mathrm{HPO}_{4}$ [pH 7.40]) before final suspension in serum-free medium. Erythrocyte contamination was reduced to $<5 \%$ by cold hypotonic lysis with no detectable loss in leukemia cell viability as determined by trypan blue dye exclusion. The final cell suspension used in the transport and drug accumulation studies contained $>95 \%$ blasts.

Experimental tumor cell lines. Ehrlich, L5178Y, and P388 cell lines were maintained as ascites tumors in $\mathrm{CF}_{1}, \mathrm{AKD}_{2} \mathrm{~F}_{1}$, and $\mathrm{DBA}_{2}$ mice, respectively. CCRF-CEM and HL-60 cells were grown in Fischer's medium supplemented with $10 \%$ horse serum. Cells were washed at least twice in PBS before use.

NBMPR binding to whole cells. Cellular $\left[{ }^{3} \mathrm{H}\right] \mathrm{NBMPR}$-binding capacity was determined by the method of Cass et al. (19). Cells (3-5 $\times 10^{6} / \mathrm{ml}$ ) were incubated in $1.5-\mathrm{ml}$ microcentrifuge tubes with $0.05-3$ $\mathrm{nM}\left[{ }^{3} \mathrm{H}\right] \mathrm{NBMPR}$ and with or without $10 \mu \mathrm{M}$ NBMPR. After $45 \mathrm{~min}$ at $20-22^{\circ} \mathrm{C}$, phthalate or silicone oil was added, and the cells were pelleted by centrifugation. The media above the oil was sampled to determine the concentration of free $\left[{ }^{3} \mathrm{H}\right] \mathrm{NBMPR}$ in each tube. The tip of the tube containing the cell pellet was cut off, and the cell pellets were solubilized in $0.5 \mathrm{ml}$ of $0.9 \mathrm{M} \mathrm{NaOH}$ plus $0.6 \%$ sodium lauryl sulfate at $60^{\circ}$ for 1 $\mathrm{h}$ or longer. $\mathrm{HCl}$ was added before counting to prevent chemiluminescence. Specific NBMPR binding was the difference between total $\left[{ }^{3} \mathrm{H}\right]$ NBMPR binding (no unlabeled NBMPR present) and nonspecific [ ${ }^{3} \mathrm{H}$ ]NBMPR binding (10 $\mu \mathrm{M}$ unlabeled NBMPR present) at each NBMPR concentration. Maximum binding capacity and the Michealis constant $\left(K_{\mathrm{m}}\right)$ were determined by Scatchard analysis $(20)$.

To determine if the solubilized cells altered counting efficiency or accuracy, Ehrlich ascites cell pellets $\left(2 \times 10^{7}\right.$ cells) were digested and neutralized as above. $\left[{ }^{3} \mathrm{H}\right]$ ara-C was added as an internal standard to these and cell-free samples. Neither the counts per minute nor the counting efficiency were measurably affected by the presence of the digested cells. No precipitate was visible.

Measurement of ara-C transport. Early in this study, ara- $\mathrm{C}$ influx was measured at room temperature using a modification of the method of Wiley et al. (15). A series of $1.5-\mathrm{ml}$ microfuge tubes containing 100 $\mu l$ of $\left[{ }^{3} \mathrm{H}\right]$ ara- $\mathrm{C}$ in media and $150 \mu$ lof phthalate oil were positioned in a microcentrifuge. Influx was started by forcefully injecting $100 \mu$ l of the cell suspension $\left(2-3 \times 10^{5}\right.$ cells) and terminated by centrifuging the cells through the oil $(8000 \mathrm{~g}$ for $30 \mathrm{~s})$. The pellets were solubilized as described for NBMPR binding. Parallel experiments with $\left[{ }^{14} \mathrm{C}\right]$ sucrose allowed correction for $\left[{ }^{3} \mathrm{H}\right] \mathrm{ara}-\mathrm{C}$ in the extracellular space. The rate of transport was taken as the slope of five to six data points over 30-60 s. Intracellular ara-C remained below $50 \%$ of the extracellular level over the interval of observation. The transport $K_{\mathrm{m}}\left(K_{\mathrm{t}}\right)$ and maximum velocity $\left(V_{\max }\right)$ of transport $\left(V_{t}\right)$ were determined by direct nonlinear fit to the MichaelisMenten equation (21) of influx data at five to six ara-C concentrations. In Novikoff hepatoma cells, the $V_{t}$ for thymidine transport was increased 3.37-fold, and the $K_{\mathrm{t}}$ was increased 2.03-fold when the temperature was increased from $24^{\circ}$ to $37^{\circ} \mathrm{C}(22)$. To estimate $V_{t}$ and $K_{t}$, for ara-C in LB-Pt we have multiplied $V_{\mathrm{t}}$ and $K_{\mathrm{t}}$ values determined at room temperature by these factors. To estimate the rate at $37^{\circ} \mathrm{C}$ at low concentrations of ara-C (i.e., $\ll K_{t}$ ), the room temperature rate was multiplied by $3.37 / 2.03$, the ratio of the correction factors for $V_{\mathrm{t}}$ and $K_{\mathrm{t}}$.

For the latter half of this study, influx was measured at $37^{\circ} \mathrm{C}$ by a method based on that of Bowen et al. $(23,24)$. To start the flux, $200 \mu 1$ of $37^{\circ} \mathrm{C}$ cell suspension $\left(6-8 \times 10^{6}\right.$ cells) was added to $200 \mu 1$ of $\left[{ }^{3} \mathrm{H}\right]$ ara$\mathrm{C}$ in a $12-\mathrm{ml}$ centrifuge tube which was agitated in a $37^{\circ} \mathrm{C}$ shaker bath. Influx was terminated by the rapid addition of $10 \mathrm{ml}$ of ice cold PBS containing $20 \mu \mathrm{M}$ dipyridamole, a potent nucleoside transport inhibitor. The cell pellets were washed twice with $5 \mathrm{ml}$ dipyridamole-saline, then solubilized and counted as above. Intracellular phosphorylation of $\left[{ }^{3} \mathrm{H}\right]$ ara-C by deoxycytidine kinase was prevented during influx experi- ments by 30 -min preincubation of the cells with $50 \mu \mathrm{M}$ deoxycytidine. Deoxycytidine had no detectable effect on ara-C transport at this concentration in Ehrlich cells (24).

Initial $\left[{ }^{3} \mathrm{H}\right]$ ara-C uptake data at $37^{\circ} \mathrm{C}$ was curvilinear (see Fig. 1), even over short intervals for most populations of LB-Pt. The data was fit by nonlinear regression (21) to equation 1 :

$[\text { IC-ara-C }]_{t}=[\text { IC-ara-C }]_{\text {infinite- }}\left(1-\mathrm{e}^{-k t}\right)+[\text { ara-C }]_{0}$,

where [IC-ara-C], is the intracellular ara-C concentration at time $t$, [ICara-C $]_{\text {infinite- } t}$ is the intracellular ara-C concentration at infinite time (i.e., equal to the extracellular ara-C concentration), and [ara-C $]_{0}$ is the level of ara-C nonspecifically bound to the cells at zero time. The initial velocity is equal to the rate constant times [IC-ara-C $]_{\text {infinite- } t}$.

Ara-C accumulation rate. Cells $\left(0.5-2 \times 10^{7}\right.$ cells $/ \mathrm{ml}$ of minimum essential medium) were incubated with $\left[{ }^{3} \mathrm{H}\right]$ ara- $\mathrm{C}$ at $37^{\circ} \mathrm{C}$ in a shaker bath. Uptake was terminated by centrifugation of cells through phthalate or silicone oil. Radioactivity was determined as described for NBMPR binding. The total aqueous volume and the extracellular space in the pellets were determined from the $\left[{ }^{3} \mathrm{H}\right]_{2} \mathrm{O}$ and $\left[{ }^{14} \mathrm{C}\right]$ sucrose space, respectively. Cellular volume was calculated as the total water space minus the sucrose space. Plots of ara-C accumulation became linear after 2 min, and the slope was assumed to reflect the rate of intracellular phosphorylation of ara-C to derivatives that can not penetrate the cell membrane. The extracellular ara-C concentration for half-maximal phosphorylation velocity $\left([\mathrm{EC} \text {-ara-C }]_{0.5}\right)$ and the maximum velocity $\left(V_{\mathrm{p}}\right)$ were estimated by nonlinear fit to the Michaelis-Menten equation (21). The concentration of intracellular ara-C for half-maximal intracellular phosphorylation $\left(K_{\mathrm{p}}\right)$ was calculated as described by Heichal et al. (14):

$K_{\mathrm{p}} \approx[\mathrm{EC} \text {-ara-C }]_{0.5}-\frac{V_{\mathrm{p}}}{2}\left(K_{\mathrm{t}} / V_{\mathrm{t}}\right)$,

where $V_{\mathrm{p}}$ is $V_{\max }$ for phosphorylation.

Analysis of intracellular radiolabel. After a 15-min incubation with $\left[{ }^{3} \mathrm{H}\right] \mathrm{ara}-\mathrm{C}, 1 \mathrm{ml}$ of the cell suspension was gently layered over $300 \mu \mathrm{l}$ of silicone oil which was, in turn, layered over $100 \mu$ lof $10 \%$ TCA in a 1.5 $\mathrm{ml}$ microcentrifuge tube. After centrifugation, the TCA layer was extracted with $150 \mu \mathrm{l} 0.5 \mathrm{M}$ triocytylamine in freon by a modification of the method of Khym et al. (25). The volumes of total and extracellular water in the extract were determined from cell suspensions incubated with $\left[{ }^{3} \mathrm{H}\right]_{2} \mathrm{O}$ or $\left[{ }^{14} \mathrm{C}\right]$ sucrose, respectively. $\left[{ }^{3} \mathrm{H}\right]$ ara-C metabolites were quantitated by anion-exchange HPLC (26). The elution position of radiolabel was compared with standard solutions of ara-C, ara-C monophosphate, ara-C diphosphate (CDP), and ara-CTP. For quantitation of unchanged $\left[{ }^{3} \mathrm{H}\right]$ ara-C in cell extracts, an aliquot of the cell extract was applied to a 0.6-ml column of Sephadex A25, which binds phosphorylated derivatives of ara-C. The column was eluted with $3 \mathrm{ml}$ of water, and the combined eluate was counted. Aliquots of $\left[{ }^{3} \mathrm{H}\right]_{2} \mathrm{O},\left[{ }^{14} \mathrm{C}\right]$ sucrose, and $\left[{ }^{3} \mathrm{H}\right]$ ara-C applied to similar columns were quantitatively recovered by this procedure.

Computer simulations. Ara-C transport and phosphorylation were simulated by applying the principles of network thermodynamics and the circuit simulation program, SPICE2. The rationale and procedure for describing biochemical pathways as analogous electrical circuits to use circuit simulation software have been previously described $(27,28)$.

Calculation of control strength for transport (CJ). Groen et al. (29) developed the concept of $C_{\mathrm{t}}$ to describe the contribution of individual enzymes in a sequential pathway to the overall flux through the pathway. Wohlhueter and Plagemann (30) defined a similar term, the coefficient of rate determination, to describe the relative importance of the capacities for membrane transport and phosphorylation as determinants of the net rate of cellular phosphorylation of nucleosides. Control strength for membrane transport would be defined as: $C_{\mathrm{t}}=\left(\delta V_{\mathrm{p}} / V_{\mathrm{p}}\right) /\left(\delta V_{\mathrm{t}} / V_{\mathrm{t}}\right)$. The $C_{\mathrm{t}}$ is the fractional change in the steady state of cellular phosphorylation that would result from a fractional change in the maximal activity of the transport carrier.

The velocity of metabolic trapping is determined by the steady state intracellular ara-C concentration and by the $V_{\mathrm{p}}$ and $K_{\mathrm{p}}$. The intracellular 
ara-C concentration is in turn determined by the relative rates of influx, efflux, and phosphorylation (30). At steady state,

infux $={ }_{\text {efflux }}^{v}+{ }_{\text {phosphorylation }}^{v}$

Equation 3 may be restated as:

$\frac{V_{\mathrm{t}} \times[\mathrm{EC}-\mathrm{ara}-\mathrm{C}]}{K_{\mathrm{t}}+[\mathrm{EC} \text {-ara-C }]}=\frac{V_{\mathrm{t}} \times[\text { IC-ara-C }]}{K_{\mathrm{t}}+[\text { IC-ara-C }]}+\frac{V_{\mathrm{p}} \times[\text { IC-ara-C }]}{K_{\mathrm{p}}+[\text { IC-ara-C }]}$,

where [EC-ara-C] and [IC-ara-C] are extracellular and intracellular concentrations of ara-C, respectively. By rearranging equation 4, [IC-ara-C] can be calculated at any [EC-ara-C] by solving this quadratic equation:

$-\left(V_{\mathrm{t}} K_{\mathrm{t}}+V_{\mathrm{p}} K_{\mathrm{t}}+V_{\mathrm{p}}[\mathrm{EC}\right.$-ara-C] $)[\mathrm{IC} \text {-ara-C }]^{2}+\left(K_{\mathrm{t}} V_{\mathrm{t}}[\mathrm{EC}\right.$-ara-C $]-K_{\mathrm{p}} K_{\mathrm{t}} V_{\mathrm{t}}$ $-\mathrm{K}_{\mathrm{t}} \mathrm{V}_{\mathrm{p}}[\mathrm{EC}$-ara-C $\left.]-K_{\mathrm{t}}^{2} V_{\mathrm{p}}\right)[\mathrm{IC}$-ara-C $]+K_{\mathrm{t}} K_{\mathrm{p}} V_{\mathrm{t}}[\mathrm{EC}$-ara-C $]=0$.

A complete kinetic analysis of transport is not necessary to estimate $C_{t}$ at low ara-C concentrations because transport is essentially first order at concentrations below $100 \mu \mathrm{M}$, (i.e. at concentrations $<20 \%$ of the $\left.K_{\mathrm{t}}\right)$. The ratio $V_{\mathrm{t}} / K_{\mathrm{t}}$ can be estimated from measurement of transport at a single low ara-C concentration (e.g. $1 \mu \mathrm{M}$ ). When [EC-ara-C] $\ll$ than $K_{t}$, equation 4 is equivalent to equation 6 .

$\frac{V_{\mathrm{t}}}{K_{\mathrm{t}}} \times[\mathrm{EC}-\mathrm{ara}-\mathrm{C}]=\frac{V_{\mathrm{t}}}{K_{\mathrm{t}}} \times[$ IC-ara-C $]+\frac{V_{\mathrm{p}} \times[\text { IC-ara-C }]}{K_{p}+[\text { IC-ara-C }]}$.

Thus, for low extracellular ara-C concentrations [IC-ara-C] can be calculated from this simplified quadratic equation:

$\frac{V_{\mathrm{t}}}{K_{\mathrm{t}}}[\text { IC-ara-C }]^{2}-\left(\frac{V_{\mathrm{t}}}{K_{\mathrm{t}}}\left[\right.\right.$ EC-ara-C] $\left.-\frac{V_{\mathrm{t}}}{K_{\mathrm{t}}} K_{\mathrm{p}}-V_{\mathrm{p}}\right)[$ IC-ara-C]

$+\frac{V_{\mathrm{t}}}{K_{\mathrm{t}}} K_{\mathrm{p}}[\mathrm{EC}-$ ara-C $]=0$.

The $C_{\mathrm{t}}$ was calculated at selected values of [EC-ara-C] by first using experimentally determined values for $V_{\mathrm{t}}$ to calculate [IC-ara-C]; $V_{\mathrm{t}}$ was then incremented by $1 \%$ and a new value for [IC-ara-C], [IC-ara-C]' was calculated. Phosphorylation velocities were calculated using the MichaelisMenten equation with $V_{\mathrm{p}}, K_{\mathrm{p}}$, and [IC-ara-C] or [IC-ara-C]'. $C_{\mathrm{t}}$ equaled the ratio of the increment in the velocity of cellular phosphorylation to the $1 \%$ increment in $V_{t}$.

\section{Results}

The initial rate of transport of $50 \mu \mathrm{M}$ ara-C was much slower in LB-Pt than in established human leukemia cell lines in culture

Table I. ara-C Transport Rate and Nucleoside Carrier Sites

\begin{tabular}{lcc}
\hline & Rate $^{*}$ & NBMPR sites \\
\hline Patients & & \\
$\quad$ Acute leukemia & $14 \pm 15$ & $4,223 \pm 4,334$ \\
& $n=45$ & $n=61$ \\
Human leukemia in cell culture & & \\
ML-1 & 805 & 139,000 \\
HL-60 & 49 & 59,000 \\
CCRF-CEM & n.d. & 183,000 \\
Mouse ascites tumors & & \\
Ehrlich & 272 & 94,000 \\
L5178Y & 105 & 74,000 \\
P388 & n.d. & 137,000 \\
\hline
\end{tabular}

n.d., not determined.

* $\mathrm{pmol} / \mathrm{min} / 10^{6}$ cells at $50 \mu \mathrm{M}\left[{ }^{3} \mathrm{H}\right] \mathrm{ara}-\mathrm{C} \pm \mathrm{SD}$.

₹ Maximal specific $\left[{ }^{3} \mathrm{H}\right]$ NBMPR-binding sites per cell \pm SD.

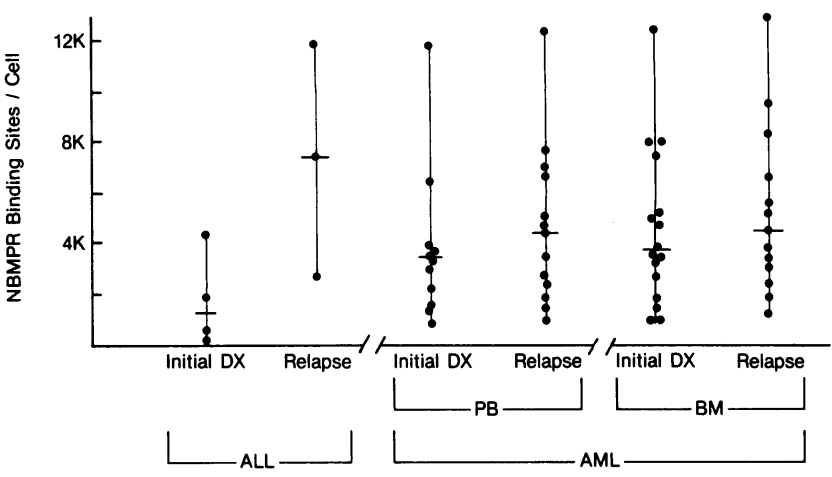

Figure 1. Cellular binding sites for $\left[{ }^{3} \mathrm{H}\right] \mathrm{NBMPR}$ in fresh human leukemia cells. Leukemia cells were isolated from peripheral blood $(P B)$ or bone marrow $(B M)$ of patients with ALL or AML at initial diagnosis $(D X)$ or in relapse from prior treatment.

or in murine ascites tumor cells (Table I). The mean velocity for cells from patients was $<2 \%$ of the rate in ML-1 cells, a human myelogenous leukemia line. LB-Pt also bound much less $\left[{ }^{3} \mathrm{H}\right] N B M P R$, a high-affinity inhibitor of nucleoside transport. The average number of $\left[{ }^{3} \mathrm{H}\right] \mathrm{NBMPR}$ sites per cell for 61 patients was 4,223 as compared with $59,000-183,000$ for various experimental cell lines. The mean dissociation constant for NBMPR binding in LB-Pt $(0.28 \pm 0.22 \mathrm{nM})$ was close to that for the experimental tumor cell types and in agreement with previously reported values $(15,19,24)$.

The number of NBMPR-binding sites in acute lymphoblastic leukemia (ALL) and AML cells at initial diagnosis and relapse are compared in Fig. 1. Lymphoblasts from patients at initial diagnosis had relatively fewer binding sites per cell than myeloblasts; medians were 1,284 and 3,435 respectively $(P<0.05)$. Cells from AML patients at initial diagnosis also had fewer sites per cell as compared with cells from patients in relapse, 3,435 vs. 4,420, respectively; however, the difference was not statistically significant. There was no difference between cells isolated from peripheral blood versus those from bone marrow.

At $1 \mu \mathrm{M}$ ara-C, the initial rate of membrane transport and the rate of net cellular accumulation were similar (Fig. 2). Inhibition of ara-C transport by $1 \mu \mathrm{M}$ NBMPR, a concentration that is $\sim 10,000$-fold higher than the dissociation constant for

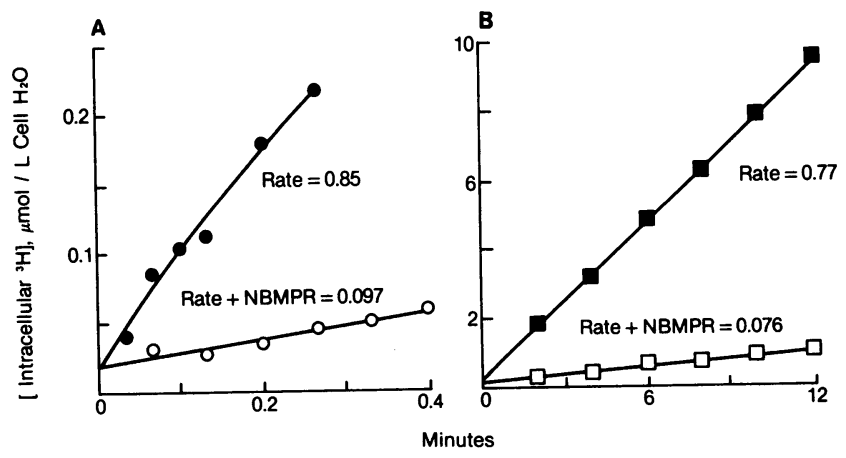

Figure 2. Membrane transport and accumulation of $\left[{ }^{3} \mathrm{H}\right] \mathrm{ara}-\mathrm{C}$ in AML cells at $37^{\circ} \mathrm{C}$. $(A)$ Transport (solid circles, open circles) or $(B)$ accumulation (solid boxes, open boxes), was measured in control cells (solid circles, solid boxes) or in cells that had been pretreated for 15 min with $1 \mu \mathrm{M}$ NBMPR (open circles, open boxes). 
$\left[{ }^{3} \mathrm{H}\right]$ NBMPR binding, was incomplete in most cell samples. For 23 samples of LB-Pt, inhibition ranged from 67 to $100 \%$, with a median of $94.9 \%$. NBMPR, which inhibits only transport, slowed ara-C transport and accumulation to the same extent. For 13 paired samples, $1 \mu \mathrm{M}$ NBMPR inhibited transport and accumulation of $1 \mu \mathrm{M}$ ara-C by $94.9 \pm 05.1$ and $93.9 \pm 5.3 \%$, respectively. These data suggest that the transport rate is the main determinant of the accumulation rate at $1 \mu \mathrm{M}$ ara-C. Myeloblasts from patients in relapse had significantly higher rates of transport at $1 \mu \mathrm{M}$ ara-C as compared with cells from patients at initial diagnosis $\left(0.35\right.$ vs. $0.21 \mathrm{pmol} / \mathrm{min}$ per $10^{6}$ cells respectively, $P$ $=0.05)$ (Fig. 3). The $V_{\mathrm{p}}$ was also elevated in relapse cells $(2.22$ vs. $1.28 \mathrm{pmol} / \mathrm{min}$ per $10^{6}$ cells, respectively, $P=0.1$ ) (Fig. 3).

Total intracellular radiolabel exceeded the extracellular concentration within 1-2 min, and the rate of accumulation remained constant after this period for at least $30 \mathrm{~min}$. Several lines of evidence indicate that the rate of accumulation of radiolabel is equivalent to the rate of initial intracellular phosphorylation of intracellular $\left[{ }^{3} \mathrm{H}\right]$ ara- $\mathrm{C}$ by deoxycytidine kinase. HPLC analysis of accumulated radiolabel revealed primarily metabolites that can be derived only from the phosphorylation of $\left[{ }^{3} \mathrm{H}\right]$ ara-C. The distribution of intracellular radiolabel after a 15 -min incubation of LB-Pt cells with 1 or $50 \mu \mathrm{M}\left[{ }^{3} \mathrm{H}\right]$ ara-C was as follows (average of two cell samples): unchanged $\left[{ }^{3} \mathrm{H}\right]$ araC, 3.8 and $43.4 \% ;\left[{ }^{3} \mathrm{H}\right]$ ara-CMP, 1.8 and $1.4 \% ;\left[{ }^{3} \mathrm{H}\right]$ ara-CDP, 7.2 and 3.7\%; $\left[{ }^{3} \mathrm{H}\right]$ ara-CTP, 81.0 and $48 \%$, at 1 and $50 \mu \mathrm{M}$ respectively. The low level of $\left[{ }^{3} \mathrm{H}\right]$ ara-CMP is an indication that initial phosphorylation of ara-C is the rate-determining step. An unidentified peak (6.4 and $4.0 \%$ at 1 and $50 \mu \mathrm{M}$ ) was observed that chromatographed close to CDP-choline and uridine monophosphate. This radiolabeled peak could thus represent $\left[{ }^{3} \mathrm{H}\right]$ araC diphosphate or $\left[{ }^{3} \mathrm{H}\right]$ ara-U monophosphate (ara-UMP). Deamination of $\left[{ }^{3} \mathrm{H}\right]$ ara- $\mathrm{C}$ to $\left[{ }^{3} \mathrm{H}\right]$ ara- $\mathrm{U}$ with subsequent phosphorylation of $\left[{ }^{3} \mathrm{H}\right]$ ara-UMP did not contribute significantly to the net uptake of radiolabel from $\left[{ }^{3} \mathrm{H}\right]$ ara- $\mathrm{C}$, because $50 \mu \mathrm{M}$ tetrahydrouridine had no effect on the rate of accumulation of 1 or $20 \mu \mathrm{M}\left[{ }^{3} \mathrm{H}\right]$ ara-C $(105 \pm 14 \%$ of control, $n=4)$, and $\left[{ }^{3} \mathrm{H}\right]$ ara$\mathrm{U}$ was accumulated beyond the extracellular concentration very slowly as compared with $\left[{ }^{3} \mathrm{H}\right]$ ara-C $(1.4 \pm 1.3 \%$ at $1 \mu \mathrm{M}, n=4)$. Inhibition of deoxycytidine kinase by pretreatment of LB-Pt with $50 \mu \mathrm{M}$ deoxycytidine for $20 \mathrm{~min}$ reduced the rate of accumulation of $\left[{ }^{3} \mathrm{H}\right]$ ara- $\mathrm{C}$ to $2.2 \pm 1.5 \%$ of control. Deoxycytidine
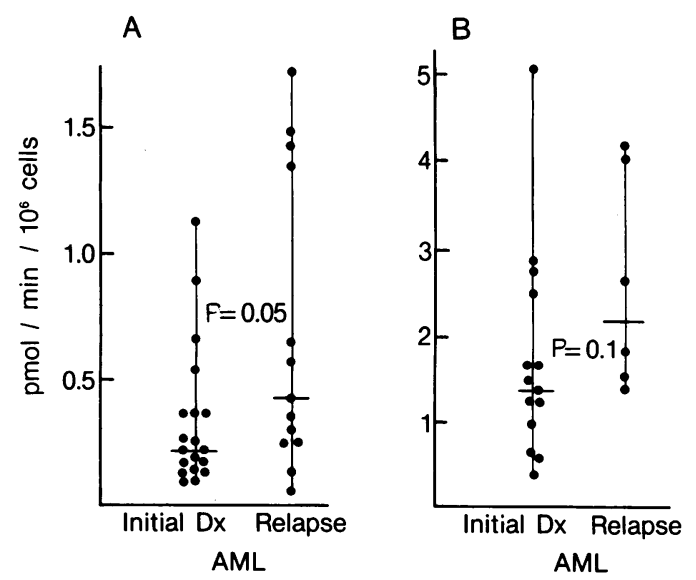

Figure 3. Transport $(A)$ and maximum accumulation $(B)$ rates in AML cells. DX, diagnosis. treatment increases the level of dCTP (unpublished data), a potent feedback inhibitor of deoxycytidine kinase (31-34), and deoxycytidine may also inhibit phosphorylation of $\left[{ }^{3} \mathrm{H}\right] \mathrm{ara}-\mathrm{C}$ by direct competion (31-34). Deoxycytidine would not be expected to inhibit accumulation of $\left[{ }^{3} \mathrm{H}\right]$ ara- $U$. Analysis of intracellular radiolabel in deoxycytidine-treated cells by HPLC revealed only unchanged $\left[{ }^{3} \mathrm{H}\right]$ ara-C.

The kinetics of transport and accumulation were quite different. Ara-C transport had a much higher $V_{\max }$, but also a higher $K_{\mathrm{m}}$ (Table II). The median $K_{\mathrm{m}}$ of $424 \mu \mathrm{M}\left(\right.$ at $37^{\circ} \mathrm{C}$ ) is near the range reported by Wiley et al. (16) for human myeloblasts $\left(255 \pm 111\right.$ at $\left.20^{\circ} \mathrm{C}\right)$. Maximal rates of ara-C accumulation were achieved at much lower concentrations. For AML cells, the mean extracellular ara-C concentration for half-maximal accumulation ([EC-ara-C $]_{0.5}$ ) was $4.9 \mu \mathrm{M}$. This value is quite low compared with reported $K_{\mathrm{m}}$ values of $14-50 \mu \mathrm{M}$ for ara-C phosphorylation by ATP in cell-free extracts of human leukemic blasts (references 32-34 and unpublished data). The [EC-ara-C $]_{0.5}$ in LB-Pt is also much lower than in L5178Y $(62 \mu \mathrm{M})$ and Ehrlich cells $(85 \mu \mathrm{M})$.

Because the rates of transport and accumulation of ara-C are similar at low ara-C concentrations, the ara- $\mathrm{C}$ can not equilibrate across the plasma membrane, and the intracellular concentration of unchanged ara-C will be lower than the extracellular level. Heichal et al. (14) have shown that the $K_{\mathrm{p}}$ can be estimated from the kinetic constants for transport and the $V_{\mathrm{p}}$ and [ECara-C $]_{0.5}$ for phosphorylation (see Methods). The average calculated value for $K_{\mathrm{p}}$ was $2.8 \mu \mathrm{M}$. The biochemical basis for this unexpectedly low apparent $K_{\mathrm{m}}$ for ara-C phosphorylation in intact LB-Pt is under investigation.

The kinetic constants for transport and phosphorylation have been used to prepare a computer simulation of the time course of initial uptake of 1 or $20 \mu \mathrm{M}$ ara-C (Fig. 4). At $1 \mu \mathrm{M}$ (Fig. 4 $A$ ), unchanged ara-C rapidly reached a steady-state intracellular concentration that was less than the extracellular level. Unchanged intracellular ara-C did not approach the extracellular concentration because it was phosphorylated almost as rapidly as it entered the cell. Once this steady-state ara-C concentration was achieved, the rate of metabolism to phosphorylated products became constant. Because the intracellular level was low com-

Table II. Kinetics of ara-C Transport and Accumulation in AML Cells

\begin{tabular}{lccc}
\hline Parameter & Mean \pm SD & & Median \\
\hline & & $n$ & \\
Transport & & & \\
$V_{\mathrm{t}}\left(\right.$ pmol/min per $10^{6}$ cells $)$ & $126 \pm 142$ & 13 & 88.3 \\
$K_{\mathrm{t}}(\mu M)$ & $556 \pm 440$ & 13 & 424 \\
$V_{\mathrm{t} / K_{\mathrm{t}}^{*}}$ & $0.47 \pm 0.45$ & 33 & 0.26 \\
Accumulation & & & \\
$V_{\mathrm{p}}\left(\right.$ pmol/min per $10^{6}$ cells $)$ & $1.98 \pm 1.20$ & 20 & 1.56 \\
[EC-ara-C $]_{0.5}(\mu M)^{\ddagger}$ & $4.88 \pm 3.19$ & 20 & 4.66 \\
$K_{\mathrm{p}}(\mu M)^{\S}$ & $2.75 \pm 2.66$ & 10 & 2.26 \\
\hline
\end{tabular}

* Calculated from measurement of $V_{\mathrm{t}}$ and $K_{\mathrm{t}}$ or from a single transport measurement at $1 \mu \mathrm{M}$ ara-C as described in Methods.

${ }^{\ddagger}$ Extracellular ara-C concentration for half-maximal accumulation rate.

${ }^{\S}$ Calculated from $V_{\mathrm{t}}, K_{\mathrm{t}}, V_{\mathrm{p}}$, and [EC-ara-C] $]_{0.5}$ according to equation 2. 


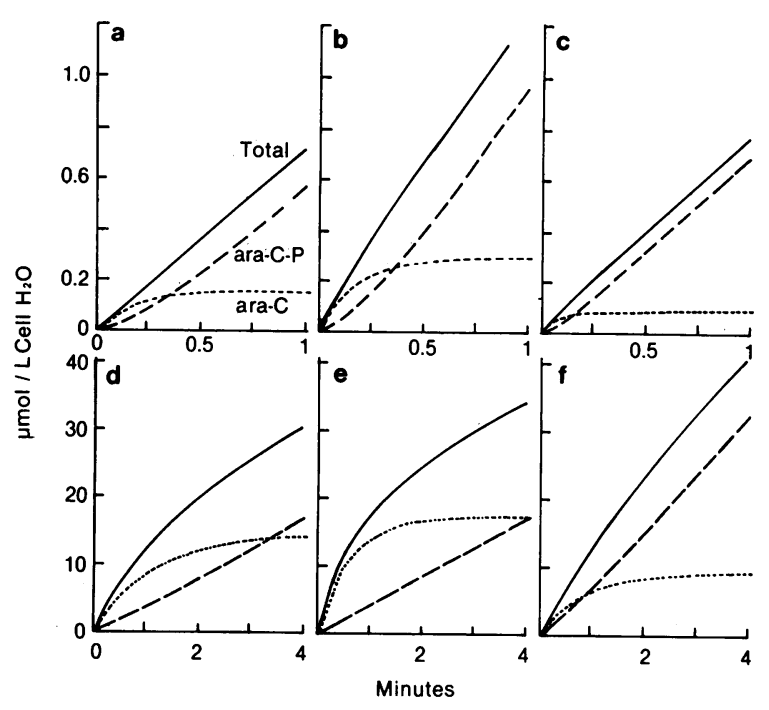

Figure 4. Computer simulation of the cellular accumulation of ara-C. Representative kinetic parameters for membrane transport and accumulation in AML were used to estimate the $K_{\mathrm{m}}$ for intracellular phosphorylation. These kinetic constants were then used to simulate ara-C accumulation at $1 \mu \mathrm{M}(a-c)$ or at $20 \mu \mathrm{M}(d-f)$. ( $a$ and $d)$ Average kinetic constants (see Table II) were used. ( $b$ and $e$ ) $V_{\mathrm{t}}$ used was twice the experimentally determined value: ( $c$ and $f$ ) $V_{\mathrm{p}}$ was doubled. ( $a$ and d) average AML. (Solid lines, total intracellular drug; dotted lines, unchanged ara-C [nucleoside]; dashed lines, phosphorylated forms of ara-C [ara-C-P]).

pared with the $K_{\mathrm{p}}$, the steady-state ara-C concentration was a major determinant of the phosphorylation rate. In Fig. $4 B$, the simulation conditions were the same except that $V_{\mathrm{t}}$ was doubled. Because ara-C could now enter the cell twice as fast, the steadystate ara-C concentration increased by $89 \%$, and the net accumulation rate increased by $67 \%$. In Fig. $4 C$, the value for $V_{\mathrm{p}}$ was doubled instead. The predicted effect was a decrease in the steady-state ara-C concentration. The increase in metabolic capacity was largely offset by decreased saturation of the phosphorylating enzyme, and the net accumulation rate was increased by only $9 \%$. These simulations suggest that at $1 \mu \mathrm{M}$ ara-C, the principal determinant of the rate of intracellular phosphorylation is the rate of membrane transport, because alterations in transport capacity have a greater effect than do changes in phosphorylation capacity. Fig. 4, $D-F$ illustrate simulations at 20 $\mu \mathrm{M}$ ara-C with AML kinetic constants, doubled $V_{\mathrm{t}}$, or doubled $V_{\mathrm{p}}$, respectively. At $20 \mu \mathrm{M}$ ara-C, increasing the transport capacity (Fig. $4 E$ ) caused a small increase in the steady-state ara$\mathrm{C}$ level; however, the steady-state concentration was already high relative to the $K_{\mathrm{p}}$. Thus, there was almost no effect on the net accumulation velocity. Doubling the $V_{\mathrm{p}}$ at $20 \mu \mathrm{M}$ ara-C (Fig. 4 $F$ ) almost doubled the accumulation rate. In contrast to predictions for $1 \mu \mathrm{M}$ ara-C (Fig. $4, A-C$ ), these simulations suggest that the principal determinant of the rate of intracellular phosphorylation at $20 \mu \mathrm{M}$ ara-C is the enzymatic phosphorylation capacity.

Measurements of the intracellular concentrations of unmetabolized ara-C in samples from six samples of LB-Pt (Table III) confirm predictions of the computer model. At $1 \mu \mathrm{M}$ extracellular ara-C, intracellular unchanged ara-C was only $0.18 \pm 0.11$ $\mu \mathrm{M}$. At $50 \mu \mathrm{M}$ extracellular ara-C, intracellular unchanged ara$\mathrm{C}$ rose to $30 \pm 12.5 \mu \mathrm{M}$. These results with LB-Pt contrast with
Table III: Dependence of Intracellular ara-C Nucleoside Concentration on the Extracellular ara-C Level

\begin{tabular}{rlll}
\hline & & \multicolumn{2}{l}{ [Intracellular ara-C] } \\
\cline { 3 - 4 } Cells & Method $^{*}$ & $1 \mu \mathrm{M}$ & $50 \mu \mathrm{M}$ \\
\hline Pt 51 & DEAE Sephadex & 0.27 & 1.02 \\
52 & HPLC & 0.14 & 0.53 \\
52 & DEAE Sephadex & 0.12 & 0.41 \\
53 & DEAE Sephadex & 0.37 & 0.76 \\
54 & DEAE Sephadex & 0.10 & 0.38 \\
55 & HPLC & 0.09 & 0.49 \\
& Mean \pm SD & $0.18 \pm 0.11$ & $0.60 \pm 0.25$ \\
& HPLC & & \\
Ehrlich & DEAE Sephadex & 0.90 & 0.94 \\
\hline
\end{tabular}

* Cells were incubated with $\left[{ }^{3} \mathrm{H}\right]$ ara-C for 20 min, then extracted with TCA. Unchanged $\left[{ }^{3} \mathrm{H}\right]$ ara-C (nucleoside) was isolated using minicolumns of DEAE-Sephadex A25 or anion-exchange HPLC.

those with Ehrlich ascites cells; which had similar intracellular and extracellular ara-C concentrations at both high and low ara$\mathrm{C}$ concentrations. These data indicate that transport capacity is in sufficient excess in Ehrlich cells to allow ara-C to equilibrate across the cell membrane.

The concentration dependence of the role of transport as a determinant of intracellular phosphorylation in LB-Pt is best illustrated by calculating the $C_{\mathrm{t}}$, defined as the role of transport capacity as a determinant on the cellular phosphorylation rate (see Methods). A $C_{\mathrm{t}}$ of 1.0 would mean that the phosphorylation rate was a direct function of the transport rate while a $C_{\mathrm{t}}$ of zero would mean that the phosphorylation rate was independent of the transport rate. The solid line in Fig. 5 is based on median values for $V_{\mathrm{t}} / K_{\mathrm{t}}, V_{\mathrm{p}}$, and ${ }^{2} K_{\mathrm{p}}$ in AML cells from Table II. At 1 $\mu \mathrm{M}$ ara-C, $C_{\mathrm{t}}$ was 0.85 , indicating that a $1 \%$ increase in $V_{\mathrm{t}}$ would cause a $0.85 \%$ increase in the cellular phosphorylation rate. The accumulation rate would increase by only $0.15 \%$ if the $V_{p}$ were increased by $1 \%$ at this low ara-C concentration. As the extracellular ara-C concentration is increased, the $C_{\mathrm{t}}$ falls because the transport capacity increases relative to the phosphorylation capacity. The LB-Pt samples have been heterogeneous with respect to their kinetic parameters for transport and phosphorylation, and therefore with respect to their dependence on the rate of transport as a determinant of the rate of intracellular metabolism. The dashed line in Fig. 5 shows the dependence of $C_{4}$ on ara-C concentration for cells from an AML patient in which transport only partially determines the rate of intracellular phosphorylation. $C_{\mathrm{t}}$ was only 0.41 , even at low ara-C concentrations. By contrast, transport is the primary determinant of the rate of ara$\mathrm{C}$ metabolism (i.e., $C_{\mathrm{t}}>0.5$ ) at concentrations up to $7 \mu \mathrm{M}$ in cells from another AML patient (dashed line).

\section{Discussion}

Ara-C is a substrate for the carrier that facilitates the nonconcentrative transport of a wide variety of nucleosides and nucleoside analogs across the cell membrane (13). Experimental tumor cells treated with inhibitors of the nucleoside carrier $(35$, 


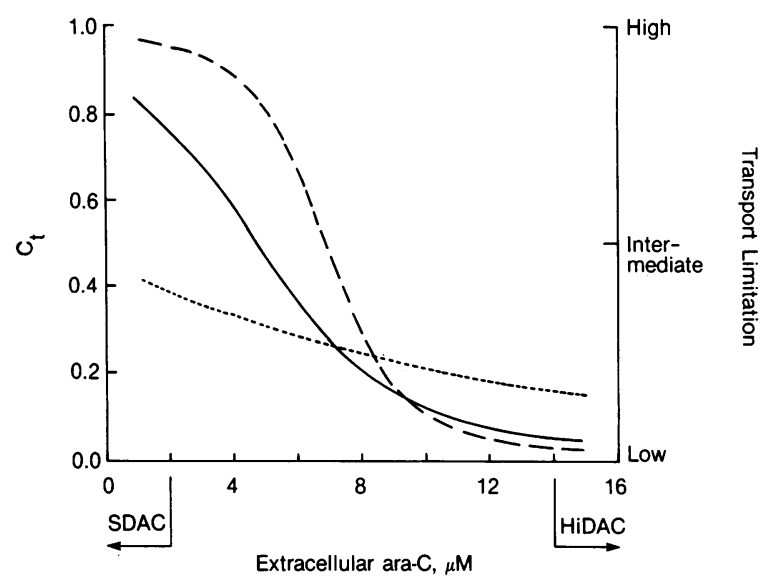

Figure 5. Concentration dependence of transport control strength as a determinant of the rate of accumulation in AML cells. The solid line is based on median kinetic constants (see Table II). The dashed and dotted lines are derived from kinetic parameters of cells from two patients, which represent extremes of high and low sensitivity to transport capacity as a determinant of the rate of ara-C accumulation. Solid line, average AML; dashed line, Pt 33; dotted line, Pt 26.

36) or mutant cells that lack this transport activity (37) are highly resistant to ara-C and other cytotoxic nucleosides. NBMPR is a potent inhibitor of nucleoside transport in most cell types although some cells possess significant NBMPR-insensitive transport capacity. NBMPR-insensitive nucleoside transport also appears to be carrier mediated with kinetic properties similar to NBMPR-sensitive transport (38).

Ara-C transport in LB-Pt was qualitatively similar to that in most experimental tumor cells. The median $K_{\mathrm{m}}$ for ara-C transport in LB-Pt $(424 \mu \mathrm{M})$ is similar to that in Novikoff hepatoma $(450 \mu \mathrm{M})$ (13), Yoshida sarcoma $(400 \mu \mathrm{M})$ (39), NIL B (226 $\mu \mathrm{M})(14)$, and Ehrlich cells $(330 \mu \mathrm{M})(24)$. An average of $95 \%$ of ara-C transport was sensitive to $1 \mu \mathrm{M}$ NBMPR. Quantitatively, however, ara-C transport rates and $\left[{ }^{3} \mathrm{H}\right] \mathrm{NBMPR}$-binding capacities in LB-Pt were much lower than in murine ascites tumors and human cells in culture. All available data suggest that LBPt possess a lower number of nucleoside carriers that are qualitatively similar to those in most experimental cell types. The biological basis for this low nucleoside carrier activity in LB-Pt is unknown.

Wiley et al. (15-17) have reported that lymphoblasts have fewer specific NBMPR-binding sites and lower transport $V_{\max }$ and $K_{\mathrm{m}}$ values as compared with myeloblasts. We also observed lower NBMPR-binding capacities in cells from ALL patients at initial diagnosis as compared with cells from AML patients (Fig. 1). Cells from ALL patients returning in relapse, however, had higher NBMPR-binding capacities than similar cells from AML patients. These data must be interpreted with caution due to the small number of ALL samples in our study to date.

When cells are exposed to $\left[{ }^{3} \mathrm{H}\right]$ ara- $\mathrm{C}$, the concentration of total intracellular radiolabel rapidly exceeds the concentration of extracellular ara-C. Ara-C is phosphorylated to ara-CMP by deoxycytidine kinase and then rapidly converted to ara-CDP and ara-CTP. These phosphorylated derivatives are not able to cross the cell membrane and therefore, they accumulate within the cell. The early rate of accumulation of radiolabel (i.e., from 2 to $30 \mathrm{~min}$ ) is thus a measure of the rate of intracellular phos- phorylation of ara-C. An alternate route for accumulation of radiolabel, deamination of ara- $\mathrm{C}$ to ara- $\mathrm{U}$, and phosphorylation of ara-U to ara-UMP, has been specifically ruled out in the studies described above.

Of interest was the increase in both the transport rate (at 1 $\mu \mathrm{M}$ ara-C) and the $V_{\mathrm{p}}$ in cells from AML patients returning in relapse as compared with patients at initial diagnosis. The biochemical basis and the pharmacologic significance of these observations warrant further investigation. The recent description of high response rates to high dose ara-C in patients with refractory AML (40) may, in part, be explained by this laboratory observation. The patients presenting for initial diagnosis usually have a larger tumor burden, and a smaller fraction of these cells may be in the DNA-synthesis phase (S phase) of the cell cycle, just as a cell culture in stationary phase contains fewer S-phase cells. The role of cytokinetics in the regulation of expression of the nucleoside carrier and ara-C anabolism is under investigation.

The cellular accumulation rate in AML cells reached a maximum at much lower extracellular ara- $\mathrm{C}$ concentrations as compared with murine ascites tumor cells. The $K_{\mathrm{m}}$ for intracellular phosphorylation of ara-C in LB-Pt, as calculated from measured values for transport kinetics, maximal accumulation velocity, and the extracellular ara-C concentration for half-maximal accumulation, was only $2-3 \mu \mathrm{M}$. This apparent $K_{\mathrm{m}}$ of deoxycytidine kinase for ara-C in situ is lower than the $K_{\mathrm{m}}$ for ara-C of $15-40 \mu \mathrm{M}$ when this enzyme is assayed in cell-free preparations with ATP as the phosphate donor (32-34). Deoxycytidine kinase is subject to highly complex controls by nucleotides ( 31$)$, and its kinetic behavior in situ could be quite different than in cellfree assays. Wohlhueter and Plagemann (30) have compared reports of kinetic constants for nucleoside kinases and cellular uptake of nucleosides and noted that the $K_{\mathrm{m}}$ for nucleoside anabolism by intact cells is nearly always less than that observed in cell-free extracts. Research is in progress to provide a biochemical explanation for the low $K_{\mathrm{p}}$ in intact LB-Pt as compared with intact murine cells and human deoxycytidine kinase in vitro. Improved understanding of the saturation kinetics for ara$\mathrm{C}$ accumulation in intact human leukemia cells may be immediately useful in dosage selection.

The rate of cellular phosphorylation of ara- $\mathrm{C}$ is determined by the properties and activity of the kinase and also by the concentration of intracellular ara-C. At intracellular concentrations of the nucleoside that are low relative to the $K_{\mathrm{p}}$, the phosphorylation rate is proportional to the substrate concentration (i.e., first order). Low transport capacity may limit the phosphorylation rate by limiting the availability of intracellular substrate. Computer simulations indicated that at low extracellular concentrations $(<1 \mu \mathrm{M})$, ara-C is phosphorylated almost as rapidly as it enters the cell, and the intracellular nucleoside concentration is much lower than the extracellular level. This prediction was confirmed by direct measurement of unchanged ara-C (Table III). The simulations also indicated that an increase in the transport capacity would have a greater effect on the cellular phosphorylation rate than an increase in deoxycytidine kinase activity. At low extracellular ara-C concentrations, an increase in transport capacity results in an increase in the concentration of intracellular ara-C (nucleoside), which results in an increase in the cellular phosphorylation rate. An increase in deoxycytidine kinase activity would not increase the cellular phosphorylation rate as much because the concentration of its substrate, intracellular ara-C would decline. Calculation of the $C_{\mathrm{t}}$ illustrates this 
relationship. For the typical AML cell, the $C_{\mathrm{t}}$ is $\sim 0.85$ at $1 \mu \mathrm{M}$ ara-C, while the deoxycytidine kinase control strength is only $\sim 0.15$.

Transport velocity is nearly proportional to concentration up to at least $100 \mu \mathrm{M}$. As described above, the rate of intracellular phosphorylation reached a maximum at relatively low concentrations. Thus, the rate of transport increases relative to the rate of phosphorylation as the extracellular ara- $\mathrm{C}$ concentration is increased. At high extracellular ara-C levels, the steady state intracellular ara-C concentration approaches the extracellular level, and variations in transport capacity have only minor effects on the intracellular ara-C level. Moreover, at intracellular concentrations above the $K_{\mathrm{m}}$ for phosphorylation, the phosphorylation rate is less dependent on the intracellular nucleoside concentration (i.e., the phosphorylation rate becomes zero order with respect to substrate), and an increase in the intracellular ara-C concentration toward the extracellular concentration has a smaller effect on the phosphorylation velocity. Thus, transport becomes less important as a determinant of the rate of cellular phosphorylation at high substrate levels. The $C_{\mathrm{t}}$ in the average LB-Pt falls to 0.5 at $\sim 5 \mu \mathrm{M}$ and is only $\sim 0.1$ at $10 \mu \mathrm{M}$. We have shown in a previous paper (24) that inhibition of ara-C transport by the epipodophyllotoxin, VM-26, slowed the rate of accumulation of $1 \mu \mathrm{M}$ ara-C in LB-Pt, but there was no effect on the accumulation rate at $50 \mu \mathrm{M}$ ara-C, because ara-C transport was rate limiting at the lower but not the higher concentration.

For cells from most AML patients, ara-C transport will be the principal rate-determining step for net uptake (i.e., $C_{\mathrm{t}}$ will be high) during low or standard dose ara-C treatment regimens (e.g., $100-200 \mathrm{mg} / \mathrm{m}^{2}$ ) that generate plasma levels below $1 \mu \mathrm{M}$ $(41,42)$. Transport will be in excess (i.e., $C_{t}$ will be low) and will not be a determinant of the rate of drug accumulation in high dose regimens (e.g., $3 \mathrm{~g} / \mathrm{m}^{2}$ ) that generate plasma levels above $50 \mu \mathrm{M}(43,44)$. Thus, high dose ara-C protocols, which generate high plasma ara-C concentrations, minimize or eliminate a potential pharmacologic obstacle and allow anabolism of ara-C to proceed at maximum rates. This difference in the relative importance of transport may contribute to the distinction in efficacy of high dose vs. standard dose ara-C treatment protocols (40).

\section{Acknowledgments}

We gratefully acknowledge the expert technical assistance of Ms. Leigh Hines and Ms. Beth Grabenstein, the statistical assistance of Dr. Timothy Morgan and Mr. Donald Hire, and the assistance of Ms. Susan Lyerly in sample aquisition and Ms. Deobrah Rosenbaum in data management. We also thank Dr. Daniel J. Fernandes for providing CCRF-CEM cells for this study.

This investigation was supported by National Institutes of Health grants CA-36000 and CA-12197.

\section{References}

1. Gale, R. P. 1979. Advances in the treatment of acute myelogenous leukemia. New Engl. J. Med. 300:1189-1199.

2. Furth, J. J., and S. S. Cohen. 1968. Inhibition of mammalian DNA polymerase by the 5'-triphosphate of $1-\beta$-D-arabinofuranosylcytosine and the 5 '-triphosphate of 9- $\beta$-D-arabinofuranosyladenine. Cancer Res. 28:2061-2067.

3. Major, P. P., E. M. Egan, G. P. Beardsley, M. D. Minden, and K. W. Kufe. 1981. Lethality of human myeloblasts correlates with the incorporation of arabinofuranosylcytosine into DNA. Proc. Natl. Acad. Sci. USA. 78:3235-3239.
4. Kufe, D. W., P. P. Major, E. M. Egan, and G. P. Beardsley. 1980. Correlation of cytotoxicity with incorporation of ara-C into DNA. $J$. Biol. Chem. 255:8997-9000.

5. Kufe, D., D. Spriggs, E. M. Egan, and D. Munroe. 1984. Relationships among ara-CTP pools, formation of (ara-C)DNA, and cytotoxicity of human leukemia cells. Blood. 64:54-58.

6. Chabner, B. A., K. R. Hande, and J. C. Drake. 1979. Ara-C metabolism: implications for drug resistance and drug interactions. Bull. Cancer(Paris). 66:89-92.

7. Harris, A. L., and D. G. Grahame-Smith. 1982. The relationship of ara-C metabolism in vitro to therapeutic response in acute myeloid leukemia. Cancer Chemother. Pharmacol. 9:30-35.

8. Drahovsky, D., and W. Kreis. 1970. Studies on drug resistance. II. Kinase patterns in P815 neoplasms sensitive and resistance to 1- $\beta$ D-arabinofuranosylcytosine. Biochem. Pharmacol. 19:940-944.

9. Schrecker, A. W. 1970. Metabolism of 1- $\beta$-D-arabinofuranosylcytosine in leukemia L-1210: nucleoside and nucleotide kinases in cellfree extracts. Cancer Res. 30:632-641.

10. Tattersal, M. H. N., K. Ganeshaguru, and A. V. Hoffbrand. 1974. Mechanisms of resistance of human acute leukemia cells to cytosine arabinoside. Brit. J. Haematol. 27:39-46.

11. Bach, M. K. 1969. Biochemical and genetic studies of a mutant strain of mouse leukemia L1210 resistant to 1- $\beta$-D-arabinofuranosylcytosine (cytarabine) hydrochloride. Cancer Res. 29:1036-1044.

12. Bhalla, K., R. Nayak, and S. Grant. 1984. Isolation and characterization of a deoxycytidine kinase-deficient human promyelocytic leukemia cell line highly resistant to $1-\beta$-D-arabinofuranosylcytosine. Cancer Res. 44:5029-5037.

13. Plagemann, P. G. W., R. Marz, and R. M. Wohlhueter. 1978. Transport and metabolism of deoxycytidine and 1- $\beta$-D-arabinofuranoysylcytosine into cultured Novikoff rat hepatoma cells, relationship to phosphorylation, and regulation of triphosphate synthesis. Cancer Res. 38:978-989.

14. Heichal, O., D. Ish-Shalom, R. Koren, and W. D. Stein. 1979. The kinetic dissection of transport from metabolic trapping during substrate uptake by intact cells. Uridine uptake by quiescent and serumactivated nil 8 hamster cells and their murine sarcoma virus-transformed counterparts. Biochem. Biophys. Acta 551:169-186.

15. Wiley, J. S., S. P. Jones, W. H. Sawyer, and A. R. P. Paterson. 1982. Cytosine arabinoside influx and nucleoside transport sites in acute leukemia. J. Clin. Invest. 69:479-489.

16. Wiley, J. S., S. P. Jones, and W. H. Sawyer. 1983. Cytosine arabinoside transport by human leukemic cells. Eur. J. Cancer \& Clin. Oncol. 19:1067-1074.

17. Wiley, J. S., J. Taupin, G. P. Jamieson, M. Snook, W. H. Sawyer, and L. R. Finch. 1985. Cytosine arabinoside transport and metabolism in acute leukemias and $\mathrm{T}$ cell lymphoblastic lymphoma. J. Clin. Invest. 75:632-642.

18. Bennett, J. M., D. Catovsky, M. T. Daniel, G. Flandrin, D. A. G. Galton, H. R. Gralnick, and C. Sultan. 1985. Proposed revised criteria for the classification of acute myeloid leukemia. Ann. Intern. Med. 103:626-629.

19. Cass, C. E., L. A. Gaudette, and A. R. P. Paterson. 1974. Mediated transport of nucleosides in human erythrocytes. Specific binding of the inhibitor nitrobenzylthioinosine to nucleoside transport sites in the erythrocyte membrane. Biochem. Biophys. Acta. 345:1-10.

20. Scatchard, G. 1949. The attraction of proteins for small molecules and ions. Ann. NY Acad. Sci. 51:660-672.

21. Duggleby, R. G. 1981. A nonlinear regression program for small computers. Anal. Biochem. 110:9-18.

22. Wohlhueter, R. M., R. Marz, and P. G. W. Plagemann. 1979. Thymidine transport in cultured mammalian cells: kinetic analysis, temperature dependence and specificity of the transport system. Biochim. Biophys. Acta. 553:262-283.

23. Bowen, D., R. B. Diasio, and I. D. Goldman. 1979. Distinguishing between membrane transport and intracellular metabolism of fluorodeoxyuridine in Ehrlich ascites tumor cells by application of kinetic and 
high performance liquid chromatographic techniques. J. Biol. Chem. 254:5333-5339.

24. White, J. C., L. H. Hines, and J. P. Rathmell. 1985. Inhibition of 1- $\beta$-D-arabinofuranosylcytosine transport and net accumulation by teniposide and etoposide in Ehrlich ascites cells and human leukemic blasts. Cancer Res. 45:3070-3075.

25. Khym, J. 1975. An analytical system for rapid separation of tissue nucleotides at low pressures on conventional anion exchangers. Clin. Chem. 21:1245-1252.

26. Rustum, Y. M., and H. D. Preisler. 1979. Correlation between leukemic cell retention of 1- $\beta$-D-arabinofuranosylcytosine 5 'triphosphate and response to therapy. Cancer Res. 39:42-49.

27. White, J. C., and D. C. Mikulecky. 1982. Application of network thermodynamics to the computer modeling of the pharmacology of anticancer agents: a network model for methotrexate as a comprehensive example. Pharmacol. \& Ther. 15:251-291.

28. White, J. C. 1986. Use of the circuit simulation program SPICE2 for analysis of the metabolism of anticancer drugs. Bull. Math. Biol. In press.

29. Groen, A. K., R. Van Der Meer, H. V. Westerhoff, R. J. A. Wanders, T. P. M. Akerboom, and J. M. Tager. 1982. Control of metabolic fluxes. In Metabolic Compartmentation. H. Sies, editor. Academic Press, Inc., New York. 9-37.

30. Wohlhueter, R. M., and P. G. W. Plagemann. 1980. The roles of transport and phosphorylation in nutrient uptake in cultured animal cells. Int. Rev. Cytol. 64:171-240.

31. Ives, D. H., and J. P. Durham. 1970. Deoxycytidine kinase. III. Kinetics and allosteric regulation of the calf thymus enzyme. J. Biol. Chem. 245:2285-2294.

32. Momparler, R. L., and G. A. Fischer. 1968. Mammalian deoxynucleoside kinases. I. Deoxycytidine kinase: purification, properties, and kinetic studies with cytosine arabinoside. J. Biol. Chem. 243:4298-4304.

33. Cheng, Y.-C., B. Domin, and L.-S. Lee. 1977. Human deoxycytidine kinase: purification and characterization of the cytoplasmic and mitochondrial isozymes derived from blast cells of acute myelocytic leukemia patients. Biochim. Biophys. Acta 481:481-492.
34. Coleman, C. N., R. G. Stoller, J. C. Drake, and B. A. Chabner. 1975. Deoxycytidine kinase: properties of the enzyme from human leukemic granulocytes. Blood. 46:791-803.

35. Paterson, A. R. P., N. Kolassa, and C. E. Cass. 1981. Transport of nucleoside drugs in animal cells. Pharmacol. \& Ther. 12:515-536.

36. Paterson, A. R. P., S.-E. Yang, E. Y. Lau, and C. E. Cass. 1979. Low specificity of the nucleoside transport mechanism of RPMI 6410 cells. Mol. Pharmacol. 16:900-908.

37. Cohen, A., B. Ulman, and D. W. Martin, Jr. 1979. Characterization of a mutant mouse lymphoma cell with deficient transport of purine and pyrimidine nucleosides. J. Biol. Chem. 254:112-116.

38. Belt, J. A. 1983. Heterogeneity of nucleoside transport in mammalian cells: Two types of transport activity in L1210 and other cultured neoplastic cells. Mol. Pharmacol. 24:479-484.

39. Mulder, J. H., and K. R. Hairgs. 1975. Cytosine arabinoside uptake by tumor cells in vitro. Eur. J. Cancer 11:373-379.

40. Capizzi, R. L., R. Davis, B. Powell, R. Cooper, J. Cuttner, and R. McIntyre. 1986. Asparaginase potentiates high dose ara-C (HiDAC) in relapsed and refractory ANLL patients. Proc. Amer. Soc. Clin. Oncol. Annu. Meet. 5:163.

41. Ho, D. H. W., and E. Frei. 1971. Clinical pharmacology of 1- $\beta$ D-arabinofuranosyl cytosine. Clin. Pharmacol. Ther. 12:944-954.

42. Weinstein, H. J., T. W. Griffin, J. Feeney, H. J. Cohen, R. D. Propper, and S. E. Sallan. 1982. Pharmacokinetics of continuous intravenous and subcutaneous infusions of cytosine arabinoside. Blood. 59: 1351-1353.

43. Capizzi, R. L., J. L. Yang, E. Cheng, T. Bjornsson, D. Sahasrabudhe, R. S. Tan, and Y. C. Cheng. 1983. Alteration of the pharmacokinetics of high-dose ara-C by its metabolite, high ara- $U$ in patients with acute leukemia. J. Clin. Oncol. 1:763-771.

44. Capizzi, R. L., M. Poole, M. R. Cooper, F. Richards, II, J. J. Stuart, D. V. Jackson, Jr., D. R. White, C. L. Spurr, J. O. Hopkins, H. B. Muss, S. A. Rudnick, R. Wells, D. Gabriel, and D. Ross. 1984. Treatment of poor risk acute leukemia with sequential high-dose ara-C and asparaginase. Blood. 63(Suppl. 3):694-700. 